\title{
Hair Damage and Wave Efficiency according to the Degree of Alkalinity in Permanent Wave
}

\author{
Nam Young Jeong, Sun Nye Lim, Chang Nam $\mathrm{Choi}^{1, *}$ \\ Interdisciplinary Program of Perfume and Cosmetics, Chonnam National University, Gwangju 500-757, Korea \\ ${ }^{1}$ Department of Polymer and Fiber System Engineering, Chonnam National University, Gwangju 500-757, Korea
}

*Correspondence to:

Choi CN,

Tel: +82-62-530-1772

Fax: +82-62-530-1779

E-mail: cnchoi@chonnam.ac.kr

Received August 3, 2012

Revised September 8, 2012

Accepted September 14, 2012
Diversification and individualization are pursued to fulfill the increasing human desire for beauty. There are many methods to change human appearances; of these, a permanent wave is often applied to improve beauty. A permanent wave uses physical and chemical methods to break and reform the bonds of natural hair. Thus, research into the optimized conditions for permanent waves is necessary to minimize hair damage and improve the efficiency of the treatment. The object of this study is to examine the effect of varying the alkalinity $(8 \%, 12 \%$, and $16 \%)$ of the permanent wave treatment on the wave efficiency, degree of hair damage via tensile strength, and degree of hair protein release. The results indicate that the treatment with the highest alkalinity $(16 \%)$ is more effective than that with $8 \%$ alkalinity; however, the degree of hair damage when treated with the $16 \%$ alkalinity wave is higher than with the $8 \%$ alkalinity wave. Additionally, hair proteins increasingly dissolve with increasing alkalinity of the permanent wave.

Key Words: Alkalinity, Hair damage, Permanent wave, Protein release, Treatment, Wave efficiency

\section{INTRODUCTION}

In modern times, people create diverse hairstyles to express their personality and beauty. These hairstyles often require treatments such as permanent waves, dyeing, and bleaching (Kim et al., 2009). The easiest way to create a hairstyle is via a permanent wave. Currently, the most commonly used method is the 'two-step permanent' method. Generally, the first agent comprises thioglycolic acid (or its salts), which is a reducing agent, cysteine, acetylcysteine, and alkali, while the second agent comprises oxidizing agents (eg., $\mathrm{NaBrO}_{3}, \mathrm{KBrO}_{3}, \mathrm{H}_{2} \mathrm{O}_{2}$, etc.) (Song, 2006). The reducing agent reduces cystine to cysteine (-SH) by breaking the S-S cystine bonding in the hair. The oxidizing agent then forms a wave by creating new S-S cystine bonds by oxidizing the reduced hair. The mechanism of wave formation is shown in Fig. 1 (Nelson \& Cox, 2000).

Due to the necessity of permanent waves, a variety of permanent agents, tools, and equipment have been developed in the cosmetology industry. However, repetitive permanent wave treatments can cause chemical and physical damage to hair. In terms of chemical damage, dyeing and bleaching are most detrimental to hair; previously damaged hair can be an obstacle to freely creating a permanent wave. In addition, physical forces such as combing are also imposed on hair during permanent wave winding (Lee, 2000). In terms of hair characteristics and damage, hair quality varies depending on personal aesthetic preferences and regular hair management. For permanent wave treatments, the permanent agent and duration of treatment must be varied depending on the condition of the hair. Since it is very difficult to restore damaged hair, it is best to prevent the damage. Hair salons should also suggest correct hair management methods at home to minimize hair damage (Shin \& Yoo, 2004). There are advantages and disadvantages to all of the current hair damage evaluation methods. In general, the methods can be classified into either a morphological approach, which

(a) This is an open-access article distributed under the terms of the Creative Commons Attribution Non-Commercial License (http://creativecommons.org/licenses/by-nc/3.0) which permits unrestricted noncommercial use, distribution, and reproduction in any medium, provided the original work is properly cited.

Copyrights @ 2012 by Korean Society of Microscopy 

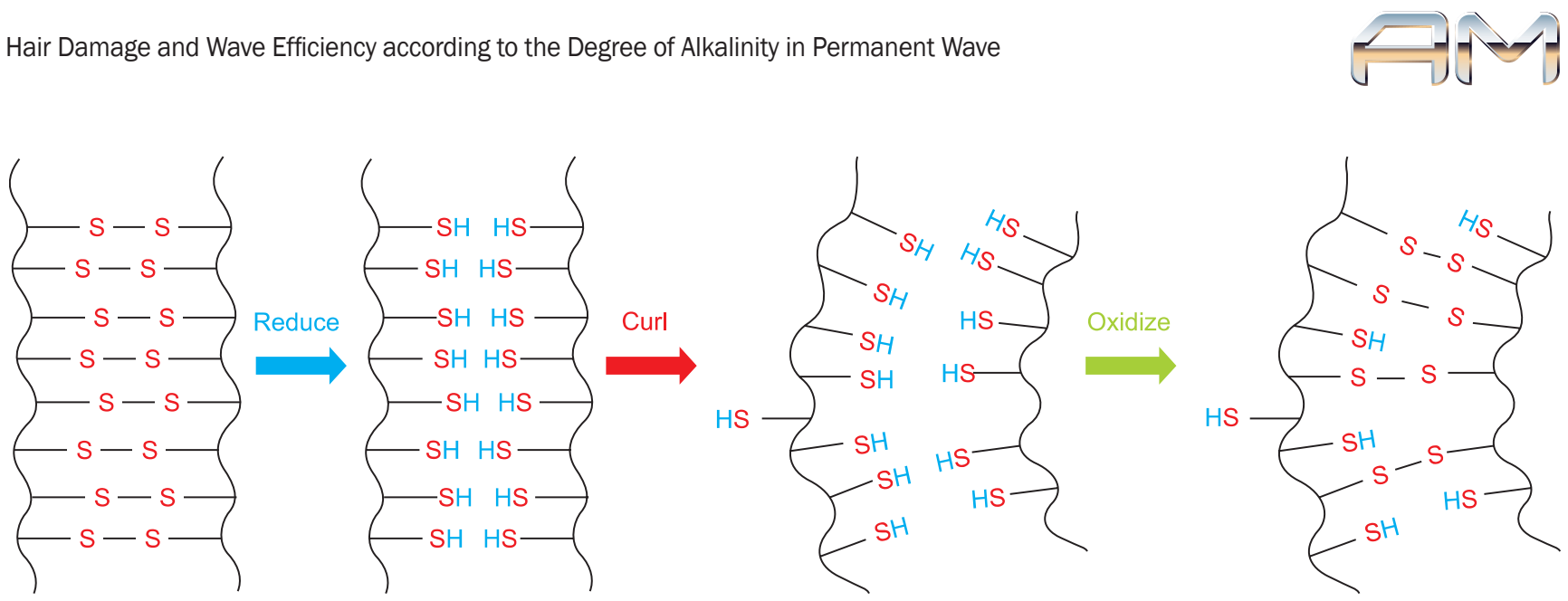

Fig. 1. Schematic representation of permanent wave production. S, sulfur; $\mathrm{H}$, hydrogen.

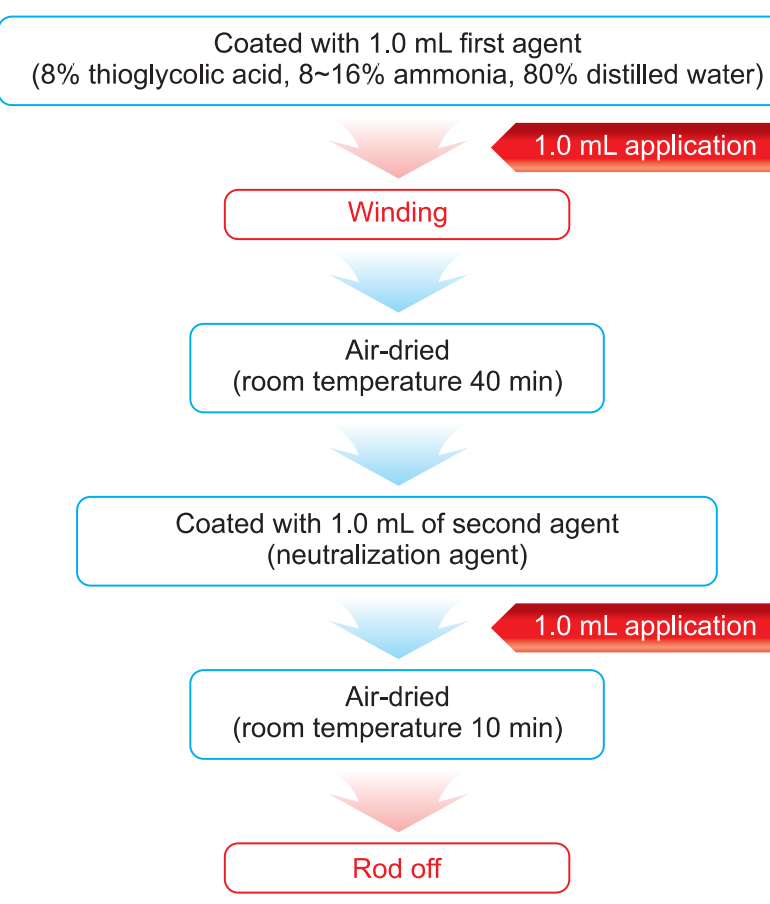

Fig. 2. Procedure for permanent wave.

includes photographing the surface of hair, measuring the protein release, or evaluating hair elasticity by measuring its tensile strength, or a chemical approach, which involves chemical analysis of the hair components (Kim, 2005).

A wide variety of permanent wave agents are commercially available, and those that comprise ammonium thioglycolate, L-cysteine, L-cysteine hydrochloric acid, and cysteamine are particularly popular. However, most of these wave agents do not indicate their alkalinity on the label. Studies such as this are essential to determine the effect of alkalinity on hair. Therefore, this study evaluates the effect of alkalinity on the efficiency of a reducing agent toward wave generation and hair damage.

\section{MATERIALS AND METHODS}

\section{Samples and Reagents}

For this study, healthy hair of women aged 30 40 years who have not chemically treated their hair with either a permanent wave or dye was used. Sample hairs were collected by binding the hair $70 \mathrm{~mm}$ away from the scalp. To minimize error, a magnifier was used to select hairs with uniform thickness. Each hair was fixed at the upper end with $10 \mathrm{~g}$ of silicon and cut to be $160 \mathrm{~mm}$ long. To remove pollutants and contaminants, the hair was washed with warm water using a weakly acidic shampoo and then rinsed in tepid water. After air-drying, the hair was sealed and stored in a desiccator with a relative humidity of $65 \%$ to avoid contamination.

For the first permanent wave agent, thioglycolic acid salt and $\mathrm{NH}_{4} \mathrm{OH}$ were acquired from Aldrich Co., Ltd. (St. Louis, MO, USA). The water used during the experiment was redistilled after being deionized. The first permanent wave agent was made by mixing ammonia $(8 \mathrm{~mL}, 12 \mathrm{~mL}$, or $16 \mathrm{~mL})$ with thioglycolic acid salt $(8 \mathrm{~mL})$ and distilled water $(80 \mathrm{~mL})$. The second agent (ie., the neutralization agent) comprised a $6 \%$ $\mathrm{H}_{2} \mathrm{O}_{2}$ solution.

\section{Test Methods}

The permanent wave was wound around no. 10 rods with a coating of the first agent on the sample hair. The hair was rinsed after $40 \mathrm{~min}$ of drying in air. After applying the second agent and leaving it for about $10 \mathrm{~min}$, the rods were removed. The sample hair was rinsed with warm water, acidrinsed, and then air-dried. The hair treatment tools used included common no. 10 rods, rubber bands, end paper, and a rattail comb. To check the wave form of the hair, it was photographed using a digital camera $(\times 1,000,000$, Samsung, Seoul, Korea). Experimental procedure was briefly appeared in Fig. 2. 
Table 1. Chemical composition of permanent wave agent A, B, and C

\begin{tabular}{clll}
\hline \multirow{2}{*}{ Product } & \multicolumn{1}{c}{ A } & \multicolumn{1}{c}{ Permanent wave treatment agent } & B \\
\cline { 2 - 4 } & Thioglycolic acid $(8 \mathrm{~mL})$ & Thioglycolic acid $(8 \mathrm{~mL})$ & Thioglycolic acid $(8 \mathrm{~mL})$ \\
Reducing agent & Ammonia $(8 \mathrm{~mL})$ & Ammonia $(12 \mathrm{~mL})$ & Ammonia $(16 \mathrm{~mL})$ \\
& Distilled water $(80 \mathrm{~mL})$ & Distilled water $(80 \mathrm{~mL})$ & Distilled water $(80 \mathrm{~mL})$ \\
Oxidizing agent & $6 \% \mathrm{H}_{2} \mathrm{O}_{2}$ & $6 \% \mathrm{H}_{2} \mathrm{O}_{2}$ & $6 \% \mathrm{H}_{2} \mathrm{O}_{2}$ \\
\hline
\end{tabular}

Table 2. Wave formation with different permanent wave agents

\begin{tabular}{lcccc}
\hline \multicolumn{1}{c}{ Category } & $\mathrm{B}_{\mathrm{pw}}(\mathrm{cm})$ & $\mathrm{A}_{\mathrm{pw}}(\mathrm{cm})$ & $\mathrm{C}_{\mathrm{f}}(\%)$ & Average (\%) \\
\hline Thioglycolic acid $(8 \mathrm{~mL})$ & 22 & 20 & 9.09 & 12.12 \\
Ammonia (8 mL) & & 19 & 13.64 & \\
Distilled water $(80 \mathrm{~mL})$ & & 19 & 13.64 & \\
Thioglycolic acid $(8 \mathrm{~mL})$ & 22 & 18 & 18.18 & 22.73 \\
Ammonia (12 mL) & & 17 & 22.73 & \\
Distilled water $(80 \mathrm{~mL})$ & & 16 & 27.27 & \\
Thioglycolic acid $(8 \mathrm{~mL})$ & 22 & 15.5 & 29.55 & 31.82 \\
Ammonia (16 mL) & & 15 & 31.82 & \\
Distilled water $(80 \mathrm{~mL})$ & & 14.5 & 34.09 & \\
\hline
\end{tabular}

\section{Measurement of Length Strain}

To assess the curl formation, the length of the curl was measured from the end of the silicon treatment to the hair end using digital calipers after the treatment was complete (Lee, et, al., 2009). The length of hair before and after the permanent wave treatment was measured and calculated based according to the following equation:

$C_{f}(\%)=\frac{\left(B_{p w}-A_{p w}\right)}{B_{p w}} \times 100(1)$

where $\mathrm{C}_{\mathrm{f}}$ refers to curl formation and $\mathrm{B}_{\mathrm{pw}}$ and $\mathrm{A}_{\mathrm{pw}}$ are the hair measurements before and after the wave treatment, respectively (Moon et al., 2010).

\section{Measurement of Tensile Strength}

To evaluate the hair damage, the tensile strength of the hair (ASTM D 751) was measured using a universal test machine (Instron Model 5543, Instron, Massachusetts, USA). The tensile strength of hair was measured by slowly extending the hair using a compression tester. The tensile strength of $2 \mathrm{~cm}$ long sample hairs, which were fixed at each end, was measured at a stretching speed of $30 \mathrm{~mm} / \mathrm{min}$ speed at $24^{\circ} \mathrm{C}$ and $40 \%$ relative humidity. From the chemically treated group, 10 hairs were randomly sampled and assessed. The measured values are stated as mean \pm standard deviation. To determine the significance of the mean, the Student's t-test was performed.

\section{Scanning Electron Microscope Observations}

To observe the hair damage, the hairs were labeled on a specimen mount, platinum-coated for $20 \mathrm{~min}$, and then observed using a scanning electron microscope $(\times 1,000$, JEOL JSM-820, Jeol, Tokyo, Japan).

\section{Release of Protein}

After the permanent wave, the hair was immediately washed and dried. The sample $(0.25 \mathrm{~g})$ then soaked in $0.1 \% \mathrm{NaOH}$ $(50 \mathrm{~mL})$ for $50 \mathrm{~min}$ and filtered. The filtered solution was measured at $320 \mathrm{~nm}$ using a ultraviolet-visible spectroscopy (UV-VIS) spectrophotometer to determine the amount of protein released from the hair via a pre-prepared standard curve.

\section{RESULTS AND DISCUSSION}

\section{Wave Efficiency}

To assess the effect of ammonia concentration on the wave efficiency and hair damage, hair samples were treated in diverse manners and the resultant hair damage was determined. The first permanent wave agent comprised thioglycolic acid, ammonia, and distilled water, while hydrogen peroxide was used as the oxidizing agent. The compositions of the permanent wave agents are stated in Table 1.

Using these compositions, a permanent wave was performed. After measuring the wave efficiency, tensile strength, and protein release and observing the hairs via scanning electron microscope, the effect of ammonia concentration on the hair damage was determined. To observe the shape of the permanent wave, the sample hairs were treated with a permanent wave then air-dried for 24 hours and photographed using a digital camera. After measuring each sample using a World Standard scale (300 mm, Sanyo, Tokyo, Japan), the results were tabulated in Table 2. According to this data, the raw sample was $22 \mathrm{~cm}$ long. When the permanent wave treatment was applied with the first agent containing $8 \mathrm{~mL}, 12 \mathrm{~mL}$, or $16 \mathrm{~mL}$ of ammonia, the length decreased to $19.3 \mathrm{~cm}, 17.0 \mathrm{~cm}$, and $15.0 \mathrm{~cm}$, respectively. Therefore, when only $8 \mathrm{~mL}$ of ammonia was used, no significant length difference was observed; however, when $16 \mathrm{~mL}$ was added, the wave was significant. In other words, when $16 \mathrm{~mL}$ of ammonia was used, the most significant result was obtained with $31.82 \% \mathrm{C}_{\mathrm{f}}$. When $8 \mathrm{~mL}$ of ammonia was added, $12.12 \%$ 

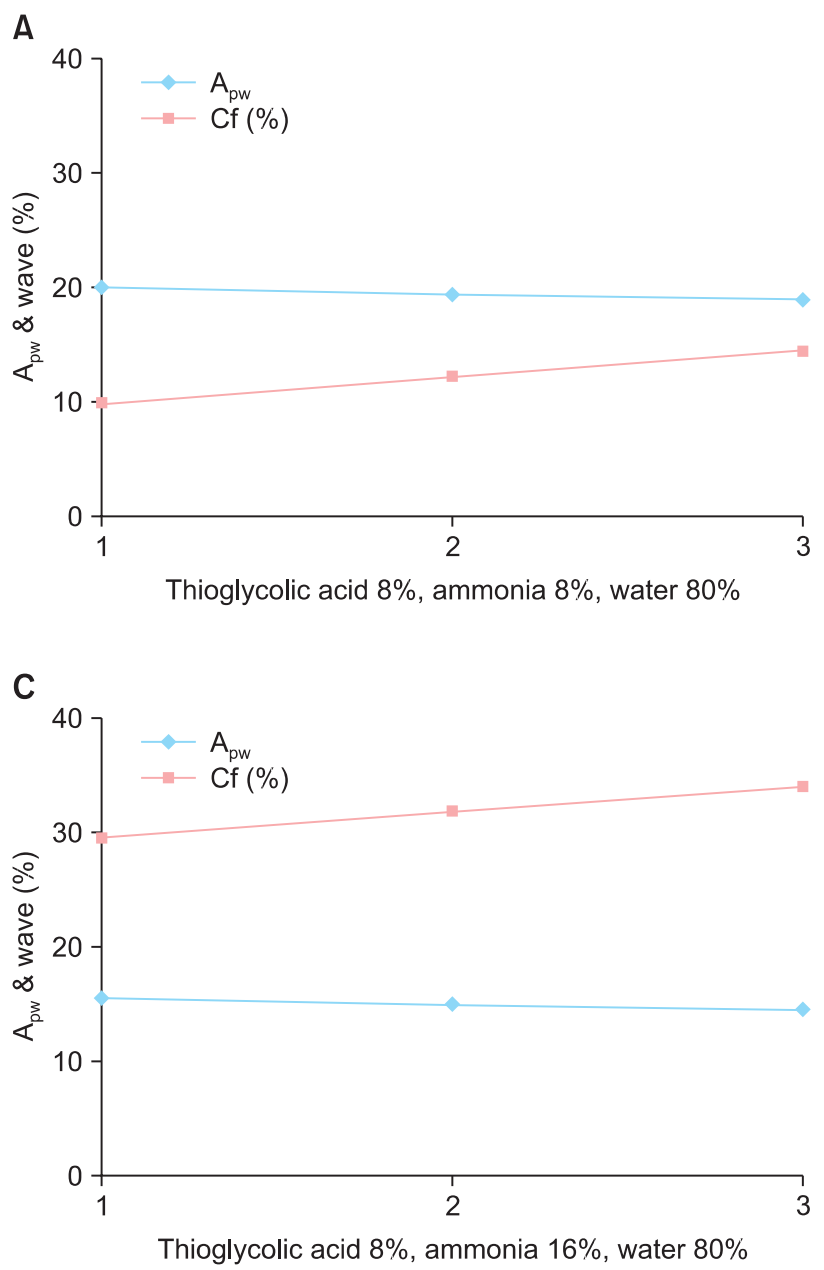

$\mathrm{C}_{\mathrm{f}}$ was obtained. However, it has been confirmed that as the concentration of ammonia increases, the hair becomes more vulnerable to damage.

Fig. 3 reveals the wave efficiency of hair when $8 \mathrm{~mL}, 12 \mathrm{~mL}$, and $16 \mathrm{~mL}$ of ammonia, respectively, was added. The wave efficiency shown in Fig. $3 \mathrm{~A}$ is relatively low at $12.12 \%$, while those shown in Fig. 3B and C were $22.73 \%$ and $31.82 \%$, respectively. Therefore, the wave efficiency was highest in Fig. 3C, which reflects the results with $16 \mathrm{~mL}$ of ammonia. Wave efficiency is closely related to the permeability of the permanent agent; therefore, epidermis permeability becomes an important factor. Since swelling, which opens the epidermis, increases as the alkalinity increases, the wave efficiency also improves (Song, 2005).

\section{Hair Damage}

Fig. 4 shows the tensile strength results with varying amounts of ammonia added to the first agent. Before chemical processing, the tensile strength of the hair was $1.2 \mathrm{~N} / \mathrm{hair}$. After treatment with a permanent wave solution containing $8 \mathrm{~mL}, 12 \mathrm{~mL}$, and $16 \mathrm{~mL}$ of ammonia, the tensile strength decreased to $1.1 \mathrm{~N} /$

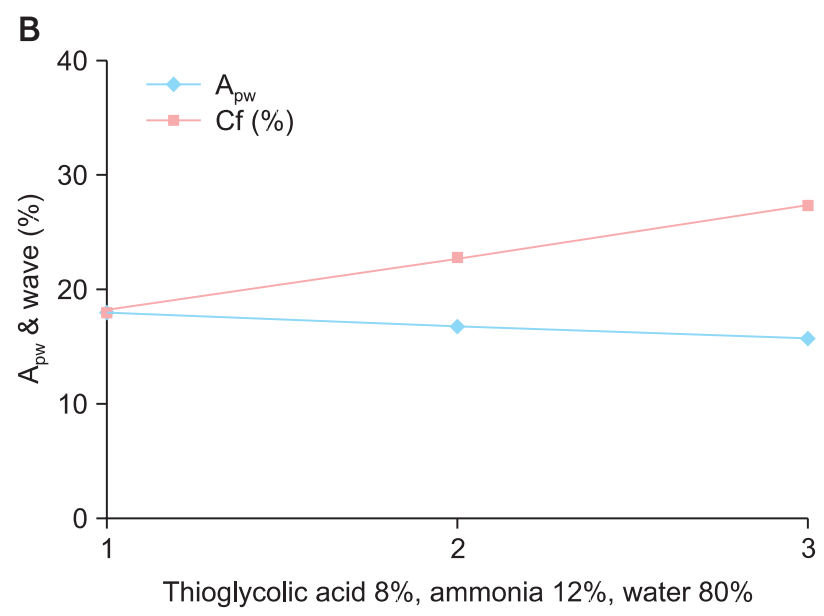

Fig. 3. Wave efficiency of hair treated with solutions with various alkalinities. (A) thioglycolic acid (8\%), ammonia (8\%), (B) thioglycolic acid (8\%), ammonia (12\%), (C) thioglycolic acid (8\%), ammonia (16\%).

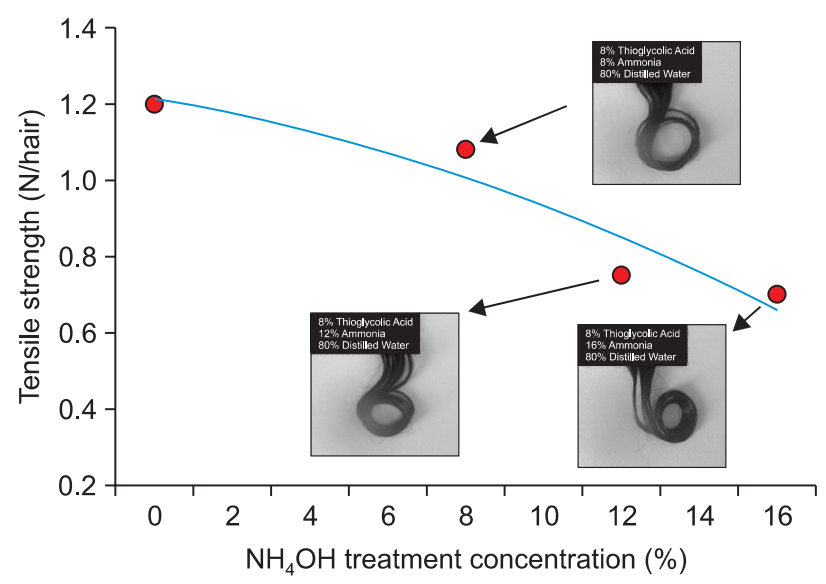

Fig. 4. Tensile strength of hair treated with solutions with various alkalinities.

hair, $0.77 \mathrm{~N} /$ hair, and $0.72 \mathrm{~N} /$ hair, respectively. In other words, even though there was not a significant difference, the tensile strength of the hair decreased as the amount of ammonia increased because the hair was damaged with increase in 


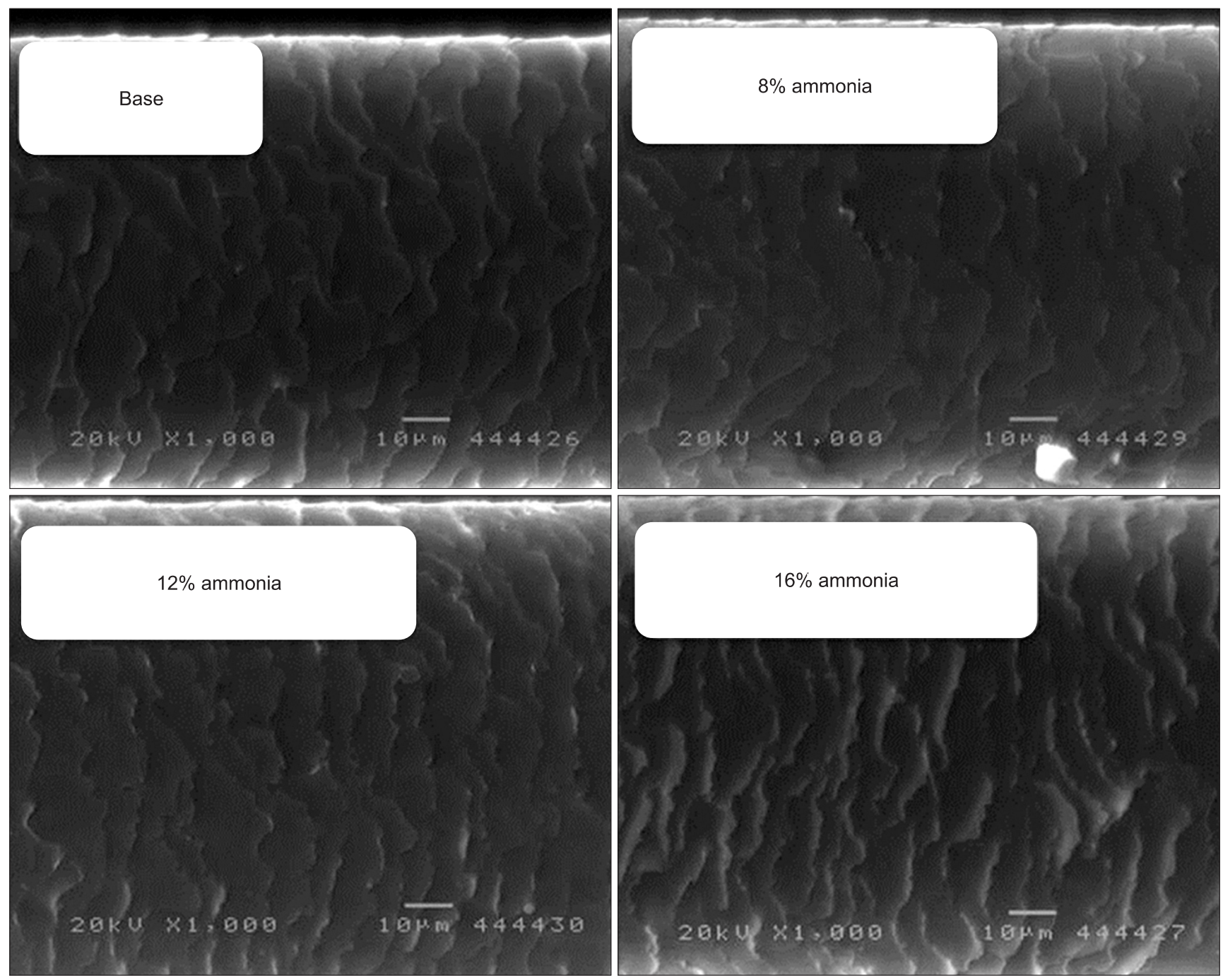

Fig. 5. Scanning electron microscope images of hair treated with solutions with various alkalinities $(\times 1,000)$.

Table 3. Protein release of hair treated with solutions with various alkalinities

\begin{tabular}{lllll}
\hline \multicolumn{1}{c}{ Sample } & Base & $8 \mathrm{ml}$ & $12 \mathrm{ml}$ & $16 \mathrm{ml}$ \\
\hline Optical density & 0.17 & 1.0 & 1.12 & 1.42 \\
& 0.18 & 1.12 & 1.20 & 1.48 \\
& 0.18 & 1.15 & 1.22 & 1.50 \\
& 0.20 & 1.19 & 1.28 & 1.52 \\
Average & 0.21 & 1.20 & 1.30 & 1.53 \\
\hline
\end{tabular}

alkalinity.

To observe the morphological changes of the hair surface after treatment with solutions containing $8 \mathrm{~mL}, 12 \mathrm{~mL}$, and 16 $\mathrm{mL}$ of ammonia, hairs were randomly sampled and observed using a scanning electron microscope (Fig. 5). The surface of the hair cuticle in a control group revealed a regularly

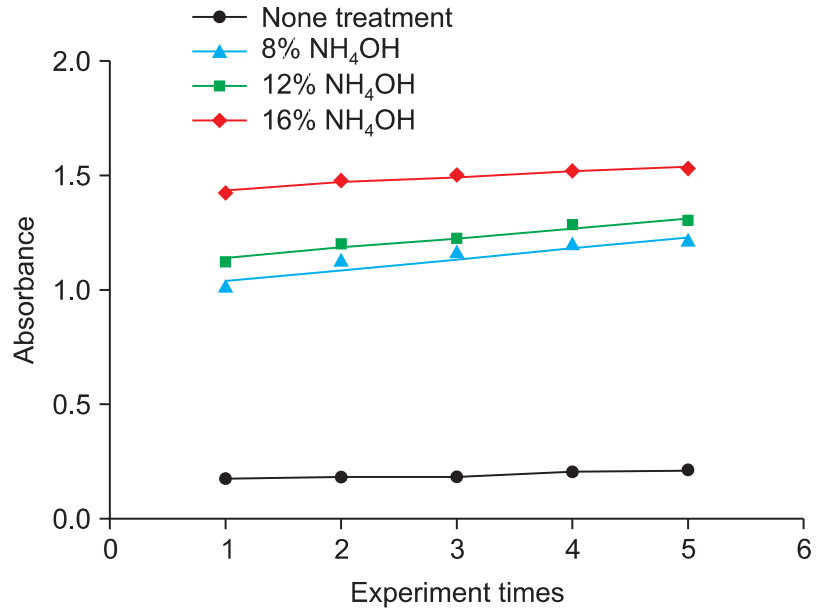

Fig. 6. Absorbance of protein solution released from hair treated with solutions with varying alkalinities. 
overlapping, closely adhered pattern. With the permanent wave treatment, as the alkalinity of increased, slightly looser patterns were detected on the surface of the hair cuticle.

Measuring the release of protein from a hair is a good method to evaluate hair damage (Lee et al., 2011). Using this method, the hair damage is evaluated based on protein content after being treated with permanent wave solution. In other words, a greater amount of protein released indicates increased hair damage. Accordingly, as the amount of ammonia increased, the amount of protein released increased as well (Fig. 6). For example, when $8 \mathrm{~mL}, 12 \mathrm{~mL}$, and $16 \mathrm{~mL}$ of ammonia was added, the average protein release was 1.132, 1.224, and 1.49, respectively (Table 3). Therefore, it was confirmed that more ammonia resulted in increased protein release.

\section{CONCLUSIONS}

The results of this study are applicable for permanent waves in the beauty industry. In this study, the effect of the concentration of ammonia on hair damage and the resultant morphological changes were examined. The following results were obtained: In terms of wave efficiency, the sample treated with a solution containing $16 \mathrm{~mL}$ of ammonia was more effective than that treated with a solution containing $8 \mathrm{~mL}$ of ammonia. When $8 \mathrm{~mL}, 12 \mathrm{~mL}$, and $16 \mathrm{~mL}$ of ammonia was used, the tensile strength of the hair was 1.1 $\mathrm{N} /$ hair, $0.77 \mathrm{~N} /$ hair, and $0.72 \mathrm{~N} /$ hair, respectively. In other words, even though there was not a significant difference, as the concentration increased, the tensile strength declined. According to observations of the hair cuticle when $8 \mathrm{~mL}, 12$ $\mathrm{mL}$, and $16 \mathrm{~mL}$ of ammonia was added, a partially loose and inflated hair cuticle was observed with $8 \mathrm{~mL}$ of ammonia; at $16 \mathrm{~mL}$, the hair cuticle was slightly loose with a partially damaged pattern. As more ammonia was added, the UVVIS absorbance of the protein released increased from 0.188 for untreated hair to 1.49 when $16 \mathrm{~mL}$ of ammonia was added. Therefore, it is confirmed that increased ammonia concentration results in increased release of protein.

Based on these results, it is necessary to further reduce hair damage and maintain healthy hair by accurately diagnosing the hair condition and examining the ammonia concentration of permanent agents when changing hairstyles using chemical agents in the beauty industry.

\section{REFERENCES}

Nelson D L and Cox M M (2000) Lehninger Principles of Biochemistry (WORTH, New York), pp. 172.

Kim K E, Lee G Y, Kim D H, Ham J H, Lee J C, and Chang B S (2009) Morphological changes of hair by repeated treatments of permanent wave. Korean J. Microscopy 39, 199-204.

Kim Y J (2005) Effect of wave formation and hair damage when used treatment on digital setting permanent. Master Thesis, Graduate School of Beauty Kwangju Woman's University.

Lee J, Lim S N, Jung N Y, Lee W E, and Choi C N (2011) Effect of solvent in the dyeing system of acid dye/human hair. Textile Coloration and Finishing 23, 250-255.

Lee J Y (2000) The effect on the attainable hair permanent and coloring by both time and temperature. J. Korean Soc. Cosm. 6, 260-261.

Lee S J, Park J A, and Kim H S (2009) The formation and endurance properties of the hair curling as a follows of containing ratio of the reductive agent in permanent wave lotion. The Journal of Beauty \& Trichology 6, 1-6.

Moon S J, Na Y N, Bae H J, and Jeun A R (2010) The effect of a order for having a permanent and dyeing on hair damage and wave. Korean $J$ Society of Beauty and Art 11, 5-19.

Shin H S and Yoo E K (2004) The observation of coating formation of damaged hair according to the chitosan treatment. J. Korean Beauty Society 10, 1-6.

Song H R (2005) Hair damage following methods and repeat of permanent wave, coloring and bleaching. Master Thesis, Konkuk University.

Song P Y (2006) Measurement of hair damage rate and mechanical properties after chemical treatment. Master Thesis, Graduate School of Engineering, Konkuk University. 